\title{
Выявление коррупционных факторов в нормативных актах методами крауд-интеллекта
}

\author{
Д.О. Рахвалова ${ }^{1}$, Г.И. Курчеева ${ }^{1}$, М.Н. Рахвалова ${ }^{2}$, М.А. Бакаев ${ }^{1}$ \\ ${ }^{1}$ Новосибирский государственный технический университет, \\ ${ }^{2}$ Новосибирский военный институт войск национальной гвардии \\ d.raxvalova@corp.nstu.ru, kurcheeva@yandex.ru, \\ rakhvalova@mail.ru, bakaev@corp.nstu.ru
}

\section{Аннотация}

В статье рассматриваются проблемы, связанные с возможностью автоматизации методики выявления коррупциогенных факторов в текстах нормативно-правовых актов и их проектов. Проведён анализ частоты выявления различных коррупциогенных факторов, предложены подходы к оценке риска присутствия таких факторов в юридическом документе. При этом частота сегментирована по идентифицированным формальным параметрам нормативно-правовых актов: год принятия, сфера правового регулирования, уровень акта. Анализ юридических документов проводился с применением подхода «крауд-интеллекта» - выполнения относительно элементарных задач по аннотированию данных для машинного обучения людьми, не являющимися экспертами в предметной области. Полученные результаты позволяют предположить дальнейшую возможность повышения эффективности антикоррупционной экспертизы на основе методов «слабого» искусственного интеллекта, т.е. поддержки принятия решений юристами-экспертами.

Ключевые слова: антикоррупционная экспертиза, правовой мониторинг, машинное обучение, аннотация данных

Библиографическая ссылка: Рахвалова Д.О., Курчеева Г.И., Рахвалова М.Н., Бакаев М.А. Выявление коррупционных факторов в нормативных актах методами крауд-интеллекта // Государство и граждане в электронной среде. Выпуск 3 (Труды XXII Международной объединенной научной конференции «Интернет и современное общество», IMS-2019, Санкт-Петербург, 19-22 июня 2019 г. Сборник научных трудов). - СПб: Университет ИТМО, 2019. С. 66-77. DOI: 10.17586/2541-979X2019-3-66-77

\section{1. Введение}

В соответствии с принятой Стратегией научно-технологического развития Российской Федерации, одним из приоритетных направлений является «переход к передовым цифровым, интеллектуальным производственным технологиям, роботизированным системам, новым материалам и способам конструирования, создание систем обработки больших объемов данных, машинного обучения и искусственного интеллекта» [12].

К приоритетам относится и цифровизация права (юридической деятельности), направлением которой является антикоррупционная экспертиза (АКЭ). АКЭ проводится на федеральном, региональном и муниципальном уровнях. Правовую базу АКЭ составляют как законы, так и подзаконные акты $[1,2,3,4]$. О масштабе деятельности по проведению АКЭ свидетельствует то, что только федеральных законов за девять месяцев 2018 г. в Российской Федерации (РФ) было принято более трехсот. При этом правила о проведении АКЭ распространяются и на проекты федеральных законов, и на подзаконные акты и их 
проекты, значит, число объектов АКЭ в разы больше. Анализ статистических данных, характеризующих деятельность министерства юстиции и иных органов государственной власти Новосибирской области (НСО) в части АКЭ НПА, показал, что число выявленных коррупциогенных факторов (КФ) снизилось за пять лет в два раза. Означает ли это, что происходит снижение количества КФ или увеличивается доля невыявленных КФ - трудно оценить, несмотря на развитие этого института в РФ. Так, например, одновременно с работой по экспертизе уполномоченных органов государственной и муниципальной власти, эта деятельность осуществляется институтами гражданского общества и гражданами (независимая АКЭ). В табл. 1 представлены данные министерства юстиции НСО [5], в Табл. 2 - данные по экспертизам (в том числе и ранее принятых НПА), проведённым в НСО всеми субъектами [6].

Таблица 1. Количество региональных НПА и проектов НПА, в отношении которых проводилась антикоррупционная экспертиза (министерство юстиции НСО), 2013-2017 гг.

\begin{tabular}{|c|c|c|}
\hline Год & $\begin{array}{l}\text { Количество НПА (в т.ч. проектов), в } \\
\text { отношении которых проведена АКЭ }\end{array}$ & $\begin{array}{c}\text { Выявленных } \\
\text { коррупциогенных факторов }\end{array}$ \\
\hline $\mathbf{2 0 1 3}$ & 3294 & 511 \\
$\mathbf{2 0 1 4}$ & 5354 & 345 \\
$\mathbf{2 0 1 5}$ & 3276 & 355 \\
$\mathbf{2 0 1 6}$ & 2878 & 298 \\
$\mathbf{2 0 1 7}$ & 3215 & 252 \\
\hline
\end{tabular}

Таблица 2. Количество региональных НПА и проектов НПА, в отношении которых проводилась антикоррупционная экспертиза (Правительство НСО), 2013-2017 гг.

\begin{tabular}{|c|c|c|c|}
\hline Год & $\begin{array}{c}\text { Кол-во подготовленных } \\
\text { проектов региональных } \\
\text { НПА }\end{array}$ & $\begin{array}{c}\text { Количество НПА (в т.ч. } \\
\text { проектов), в отношении } \\
\text { которых проведена АКЭ }\end{array}$ & $\begin{array}{c}\text { Выявленных } \\
\text { коррупцогенных } \\
\text { факторов }\end{array}$ \\
\hline $\mathbf{2 0 1 3}$ & Сведения отсутствуют & 6382 & 600 \\
$\mathbf{2 0 1 4}$ & 5918 & 10707 & 864 \\
$\mathbf{2 0 1 5}$ & 6207 & 8715 & 1450 \\
$\mathbf{2 0 1 6}$ & 4951 & 6206 & 461 \\
$\mathbf{2 0 1 7}$ & 4929 & 6493 & 332 \\
\hline
\end{tabular}

Констатируя, что ни одна математическая модель и программа не сможет в полной мере заменить эксперта-человека с адекватным уровнем профессиональной юридической подготовки, растущие объемы в сфере законотворческой деятельности требуют автоматизации деятельности. Таким образом, целью данного исследования является не просто выявление КФ в текстах НПА и их проектов, а исследование возможностей применения искусственного интеллекта для анализа содержания НПА, что призвано повысить эффективность проведения АКЭ.

\section{2. Проблемы антикоррупционной экспретизы и подходы к их решению}

О важности и интеграции АКЭ в российскую правовую систему свидетельствует тот факт, что по состоянию на осень 2018 года в реестр независимых экспертов, получивших аккредитацию на проведение АКЭ НПА и проектов НПА, включено почти 2500 физических лиц и 400 юридических лиц [7]. Однако проблемы в области АКЭ только растут, что связано с:

1. Увеличением объема работ, приходящегося на каждого эксперта.

2. У Уовнем профессиональной подготовки конкретной группы экспертов, работающих с конкретным правовым материалом при всей тщательности отбора их кандидатур.

3. Особенностями размещения проектов НПА, требующих АКЭ, на сайтах органов местного самоуправления или субъектов РФ. Как правило, они размещаются в 
общей массе документов, что затрудняет их выборку и в дальнейшем, отслеживание качества проведения экспертизы (например, [8]) или не содержат текстов заключений о проведении экспертизы (например, [9]).

4. «Размытостью» формулировки отдельных КФ, что создает дополнительные трудности при установлении квалифицирующих признаков КФ, и неоднородность подходов правоприменительных органов.

В рамках более детального изучения пункта 4, авторами с использованием метода простой случайной выборки были исследованы 350 нормативных актов, обобщенная информация по которым представлена в табл. 3.

Таблица 3. Неоднородность подходов к выявлению коррупциогенных факторов

\begin{tabular}{|l|c|}
\hline \multicolumn{1}{|c|}{ Факт выявления/ не выявления КФ } & $\begin{array}{c}\text { Количество } \\
\text { судебных актов }\end{array}$ \\
\hline $\begin{array}{l}\text { АКЭ установлено наличие КФ; суд отказал в признании НПА не } \\
\text { действующим }\end{array}$ & $9(2.57 \%)$ \\
АКЭ КФ не обнаружен; суд признал НПА не действующим & $14(4 \%)$ \\
АКЭ установлено наличие КФ; суд признал НПА не действующим & 0 \\
АКЭ КФ не обнаружен; суд отказал в признании НПА не действующим & $169(49.28 \%)$ \\
Данные об АКЭ отсутствуют; суд признал НПА не действующим & $28(8 \%)$ \\
Данные об АКЭ отсутствуют; суд отказал в признании НПА не & $62(17.71 \%)$ \\
действующим & $17(4,85 \%)$ \\
АКЭ не проводилась; суд признал НПА не действующим & $52(14.85 \%)$ \\
АКЭ не проводилась; суд отказал в признании НПА не действующим & \\
\hline
\end{tabular}

В такой ситуации при проведении АКЭ НПА или его проекта определенную помощь могут оказать методические рекомендации, разработанные Министерством юстиции РФ (Методика) [10], [11].

В соответствии с Методикой к КФ, устанавливающим для правоприменителя необоснованно широкие пределы усмотрения или возможность необоснованного применения исключений из общих правил, относятся десять факторов [10].

Соблюдение принципа проверяемости результатов АКЭ достигается при наличии возможности проверки истинности полученных результатов, то есть оценка коррупциогенности положения НПА проведена в строгом соответствии с указанными Методикой, выводы логичны, имеют законное основание и могут быть воспроизведены в случае проведения повторной экспертизы [10, с. 27]. При этом размытость легальных формулировок влечет неоднородность правоприменительной практики. Наличие или отсутствие того или иного КФ по-разному оценивается, например, субъектами, осуществляющими экспертизу, и судами.

По данным Методики первое место среди КФ по выявляемости в НПА субъектов РФ занимает широта дискреционных полномочий [10, с. 29]. Распространенность данного КФ подтверждается также проведенной авторами настоящего исследования выборкой судебных актов по делам о признании недействующими НПА. Так, из 350 изученных судебных актов Верховного Суда РФ, принятых по данной категории дел, в 136 (39\%) случаях рассматривался вопрос о наличии (отсутствии) широты дискреционных полномочий.

Еще одним распространенным КФ является юридико-лингвистическая неопределенность - вопрос о его наличии (отсутствии) рассматривался 112 раз (32\%). При этом нельзя не отметить неоднозначное толкование одного и того же КФ судами разных инстанций, что встречается в 45 \% случаев оспаривания решения суда первой инстанции в апелляционном порядке.

Достаточно сложно перевести на машиночитаемый уровень текст НПА с целью выявления КФ в случае отсутствия или неопределенности условий или оснований для принятия решений. Однако выявление коррупциогенности в виде отсутствия четко 
установленных сроков оказания государственной (муниципальной) услуги и т.п. представляется вполне реальным. А это наиболее часто встречающееся нарушение.

Одним из проявлений неопределенности условий и оснований для принятия решения является часто встречаемое нарушение в виде определения компетенции органа государственной власти или местного самоуправления по формуле «вправе» - это диспозитивное установление возможности совершения государственным органом, органом местного самоуправления или организацией (их должностными лицами) действий в отношении граждан и организаций.

Для выявления и оценки рассматриваемого коррупциогенного фактора целесообразно использование методик лингвистического анализа $[14$, с. 17-21] посредством осуществления автоматизированного поиска, в частности по следующим позициям в зависимости от возможного проявления широты дискреционных полномочий (Рис. 1).

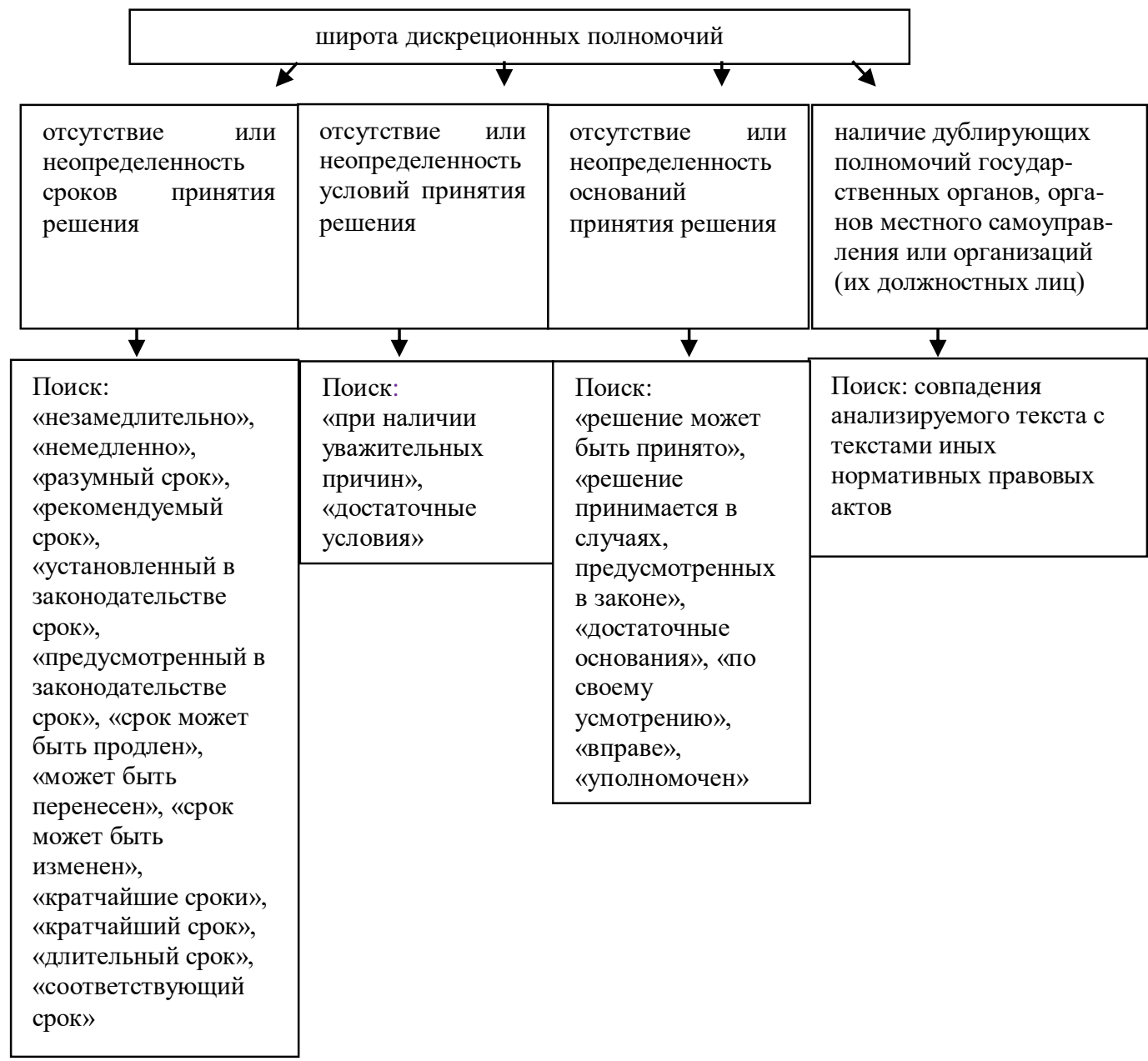

Рис. 1. Схема выявления в тексте маркеров широты дискреционных полномочий

Еще одним проявлением коррупциогенности НПА (его проекта) является юридиколингвистическая неопределенность - употребление не устоявшихся, двусмысленных терминов и категорий оценочного характера. Заметим, что в полном объеме избежать использования оценочных понятий в действующем российском законодательстве не удастся. Например, гражданскому законодательству, для которого характерно наличие 
множества диспозитивных норм права, известны такие как «разумный срок», «несоразмерность вреда» и т.д. Наличие оценочных категорий в ряде случаев в тексте НПА оправданно и не может рассматриваться в качестве коррупциогенности. «Лексикотерминологическая» неоднозначность всегда является серьезным недостатком такой развитой информационной системы, как система НПА. Для единства юридической терминологии необходимо, чтобы при обозначении в нормативном тексте определенного понятия последовательно употреблялся один и тот же термин. Для выявления и оценки рассматриваемого коррупциогенного фактора (см. Рис. 2) также представляется возможным использование методик лингвистического анализа $[14$, с. 20].

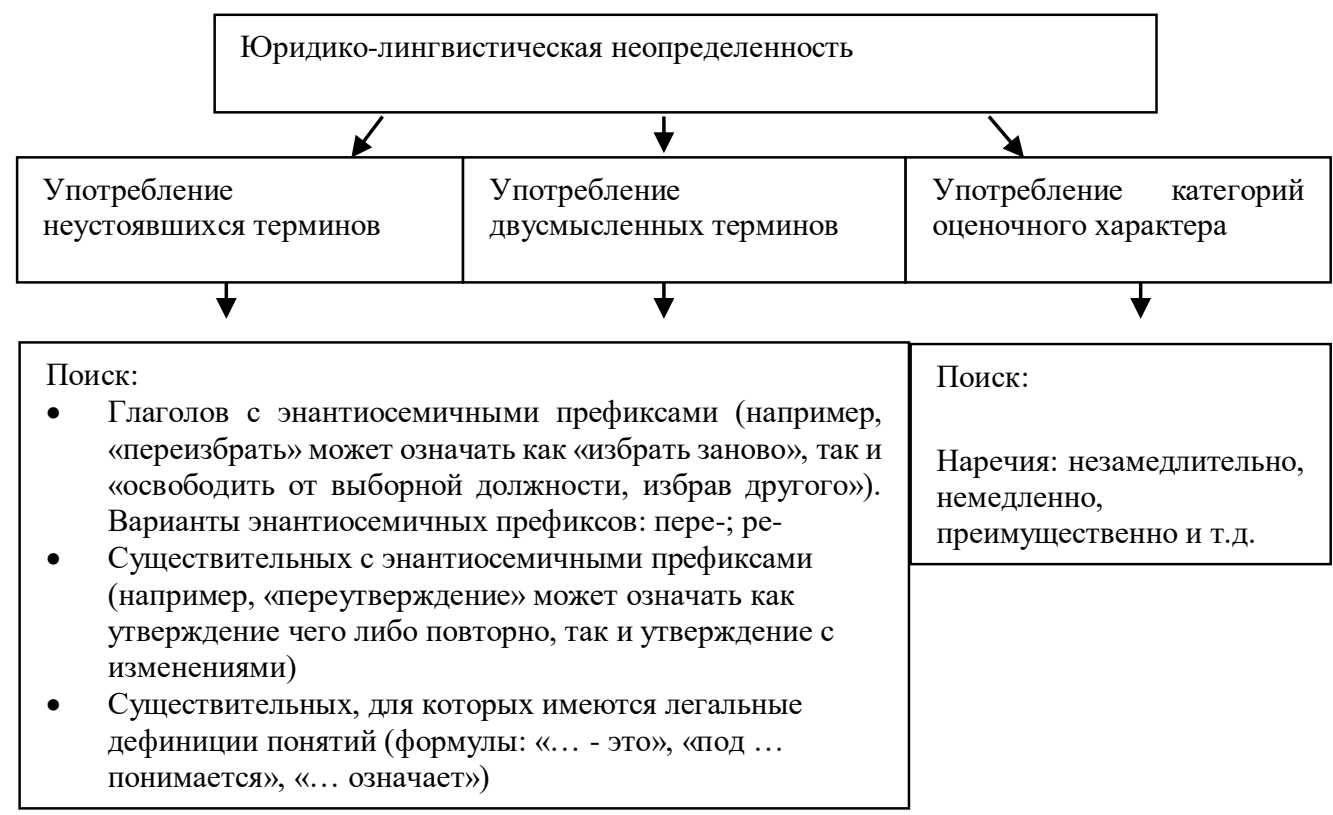

Рис. 2. Схема выявления в тексте маркеров юридико-лингвистической неопределенности

В табл. 4 мы обобщаем наши представления о возможности автоматизации АКЭ по группам КФ. Ниже мы приводим дополнительные пояснения для факторов, автоматизированный анализ которых был признан возможным.

Широта дискреционных полномочий. При помощи лингвистического поиска слов и словосочетаний «незамедлительно», «немедленно», «разумный срок», «рекомендуемый срок», «установленный в законодательстве срок», «предусмотренный в законодательстве срок», «срок может быть продлен», «может быть перенесен», «срок может быть изменен», «кратчайшие сроки», «кратчайший срок», «длительный срок», «соответствующий срок», уважительных причин», «достаточные условия», «решение может быть принято», «решение принимается в случаях, предусмотренных в законе», «достаточные основания», «по своему усмотрению», «вправе», «уполномочен» и проч., а также совпадений анализируемого текста с текстами иных НПА.

Определение компетенции по формуле «вправе». При помощи лингвистического поиска слов и словосочетания «вправе», «имеет право», «обладает правом», а также их синонимов, например, «может», «определяет», «устанавливает», «решает», «принимает решение», «уполномочен», «имеет полномочия».

При этом сам факт выявления указанных выше слов и словосочетаний показывает лишь на высокий риск наличия КФ (с точки зрения оценки степени коррупциогенности не имеет 
значения их количественное значение). Требуются специальные знания эксперта для установления смысла конкретной нормы права и окончательного вывода.

Таблица 4. Возможность автоматизированного анализа по группам коррупциогенных факторов

\begin{tabular}{|c|c|c|}
\hline № & $\begin{array}{c}\text { Коррупциогенные } \\
\text { факторы }\end{array}$ & Возможность автоматизированного анализа \\
\hline 1. & $\begin{array}{l}\text { Широта дискреционных } \\
\text { полномочий }\end{array}$ & $\begin{array}{l}\text { Автоматизированный поиск конструкций, свидетельствующих } \\
\text { об отсутствии или неопределенности сроков, условий или } \\
\text { оснований принятия решения, наличии дублирующих } \\
\text { полномочий государственных органов, органов местного } \\
\text { самоуправления или организаций (их должностных лиц). }\end{array}$ \\
\hline 2. & $\begin{array}{l}\text { Определение компетенции } \\
\text { по формуле «вправе» }\end{array}$ & 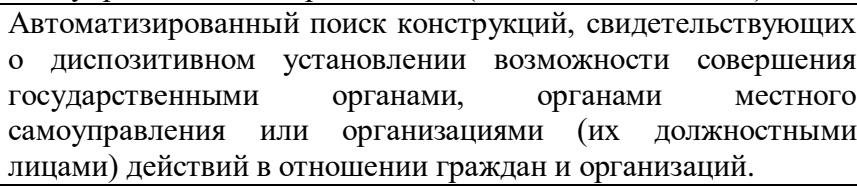 \\
\hline 3.) & $\begin{array}{l}\text { Отсутствие или неполнота } \\
\text { административных } \\
\text { процедур }\end{array}$ & $\begin{array}{l}\text { Автоматизированный анализ затруднен, в силу наличия } \\
\text { большого количества разнообразных административных } \\
\text { процедур, содержание которых не совпадает. Соответственно, } \\
\text { в них сложно выявить общие закономерности. }\end{array}$ \\
\hline 4. & Нормативные коллизии & $\begin{array}{l}\text { Автоматизированный анализ затруднен. Коллизия в праве - это } \\
\text { явление, когда две и более нормы содержат разные правила } \\
\text { поведения, применяемые в одних и тех же условиях. Однако в } \\
\text { противоречащих нормах не обязательно используются схожие } \\
\text { языковые конструкции. Необходимо наличие специальных } \\
\text { знаний эксперта для выявления таких норм. }\end{array}$ \\
\hline 5. & $\begin{array}{l}\text { Юридико-лингвистическая } \\
\text { неопределенность }\end{array}$ & $\begin{array}{l}\text { Автоматизированный поиск неустоявшихся, двусмысленных } \\
\text { терминов и категорий оценочного характера }\end{array}$ \\
\hline
\end{tabular}

Отсутствует возможность автоматизированного анализа по следующим группам коррупциогенных факторов:

- выборочное изменение объема прав;

- чрезмерная свобода подзаконного нормотворчества;

- принятие нормативного правового акта за пределами компетенции;

- заполнение законодательных пробелов при помощи подзаконных актов в отсутствие законодательной делегации соответствующих полномочий;

- отказ от конкурсных (аукционных) процедур;

- наличие завышенных требований к лицу, предъявляемых для реализации принадлежащего ему права;

- злоупотребление правом заявителя государственными органами, органами местного самоуправления или организациями (их должностными лицами).

Отсутствие или неполнота административных процедур. Возможна автоматизация анализа отдельных видов административных процедур. Например, административных процедур по оказанию государственных услуг.

Нормативные коллизии. Автоматизированный анализ возможен в тех случаях, когда противоречащие нормы все же содержат схожие языковые конструкции, для выявления которых применим лингвистический поиск.

Юридико-лингвистическая неопределенность. Для автоматизации поиска необходимо создание словаря легальных дефиниций понятий. О наличии КФ может свидетельствовать, в частности, содержание тексте определения понятия, уже имеющего легальную дефиницию. Также необходимо создание базы категорий оценочного характера. При этом сам факт выявления в тексте таких понятий и категорий показывает лишь высокий риск наличия КФ (с точки зрения оценки степени коррупциогенности не имеет значения их 
количественное значение). Требуются специальные знания эксперта для установления смысла конкретной нормы права и окончательного вывода.

\section{3. Анализ нормативных актов методами крауд-интеллекта}

Для проведения анализа НПА на предмет КФ, автоматизация выявления которых была признана потенциально возможной, мы задействовали 30 участников студенческой лаборатории крауд-интеллекта *** университета. В качестве источников данных выступали сайт «Верховный суд Российской Федерации» (http://www.vsrf.ru/) и ГАС «Правосудие» (https://sudrf.ru/). Всего было рассмотрено 4763 документов: судебные акты по результатам рассмотрения заявлений об оспаривании НПА и собственно сами НПА. По результатам текстологического изучения каждого документа участником делалась запись в бланке. Конкретно в рамках анализа было рассмотрено:

- 3050 документов по АКЭ;

- 429 по коррупциогенным факторам;

- 247 по фактору юридико-лингвистической неопределенности;

- 65 по фактору определения компетенции по формуле «вправе»;

- 699 по нормативным коллизиям;

- 225 по пункту 3 методики проведения АКЭ НПА и проектов НПА;

- 48 по пункту 4 методики проведения АКЭ НПА и проектов НПА.

В ходе исследования посредством использования ресурсов открытого доступа был проведен выборочный анализ судебных актов по делам об оспаривании НПА. В результате выявлены и предлагаются для автоматизации процессов поиска следующие параметры НПА, влияющие на их признание недействующим полностью или в части:

1. Год принятия НПА (Табл. 5).

2. Сфера общественной жизни, регулируемая НПА (Табл. 6).

3. Уровень НПА: федеральный, региональный, местный (Табл. 7)

Таблица 5. Годы принятия НПА и признание их недействующими

\begin{tabular}{|c|c|c|c|c|c|c|c|c|c|c|c|c|c|c|c|c|c|c|}
\hline Показатель & बे & बे & 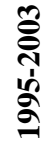 & ষ্ণ & 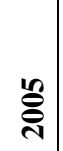 & ఫ్రి & હ్ & 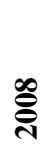 & 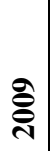 & 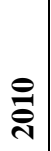 & $\overline{\overline{\mathcal{N}}}$ & 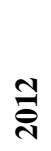 & 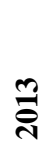 & $\stackrel{\nabla}{\bar{ন}}$ & 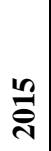 & $\stackrel{0}{\stackrel{\sim}{*}}$ & $\overline{\bar{\lambda}}$ & $\stackrel{\infty}{\bar{乛}}$ \\
\hline $\begin{array}{c}\text { Количество } \\
\text { дел об } \\
\text { оспаривани } \\
\text { и данного } \\
\text { вида НПА }\end{array}$ & 1 & 1 & 0 & 1 & 1 & 5 & 5 & 26 & 11 & 33 & 9 & 34 & 20 & 14 & 22 & 17 & 8 & 2 \\
\hline $\begin{array}{c}\text { Количество } \\
\text { НПА, } \\
\text { признанных } \\
\text { недейству- } \\
\text { ющими } \\
\text { полностью } \\
\text { или в части }\end{array}$ & 1 & 0 & 0 & $\overline{0}$ & 1 & 4 & 4 & 17 & 6 & 28 & 6 & 31 & 8 & 9 & 18 & 8 & 2 & 1 \\
\hline $\begin{array}{c}\text { Процент } \\
\text { признания } \\
\text { НПА } \\
\text { недействую } \\
\text { щими }\end{array}$ & 100 & 0 & 0 & 0 & 100 & 80 & 80 & 65 & 55 & 85 & 67 & 91 & 40 & 64 & 82 & 46 & 25 & 50 \\
\hline
\end{tabular}


Таблица 6. Сферы действия НПА и признание их недействующими

\begin{tabular}{|c|c|c|c|c|c|c|c|c|c|c|}
\hline \multirow[b]{2}{*}{ Показатель } & \multicolumn{7}{|c|}{ Сфера публичного права } & \multicolumn{3}{|c|}{$\begin{array}{c}\text { Сфера частного } \\
\text { права }\end{array}$} \\
\hline & 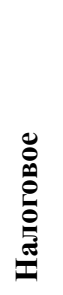 & 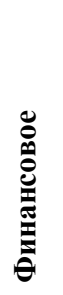 & 兽 & 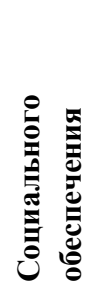 & 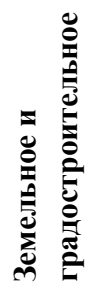 & 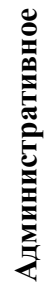 & 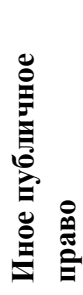 & 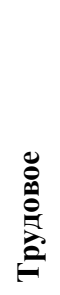 & 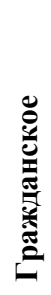 & 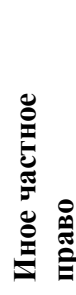 \\
\hline $\begin{array}{c}\text { Количество дел об } \\
\text { оспаривании } \\
\text { данного вида НПА }\end{array}$ & 1 & 5 & 6 & 13 & 20 & 56 & 99 & 1 & 8 & 1 \\
\hline $\begin{array}{c}\text { Количество НПА, } \\
\text { признанных } \\
\text { недействующими } \\
\text { полностью или в } \\
\text { части }\end{array}$ & 1 & 5 & 4 & 9 & 17 & 36 & 63 & 0 & 6 & 0 \\
\hline $\begin{array}{c}\text { Процент признания } \\
\text { НПА } \\
\text { недействующими }\end{array}$ & 100 & 100 & 67 & 69 & 85 & 64 & 64 & 0 & 75 & 0 \\
\hline
\end{tabular}

Таблица 7. Уровень НПА и признание его недействующим

\begin{tabular}{|c|c|c|c|c|c|}
\hline Показатель & \multicolumn{2}{|c|}{ Федеральный } & \multicolumn{2}{|c|}{ Региональный } & Муници- \\
\cline { 2 - 5 } & закон & $\begin{array}{c}\text { подзаконный } \\
\text { акт }\end{array}$ & закон & $\begin{array}{c}\text { подзаконный } \\
\text { акт }\end{array}$ & $\begin{array}{c}\text { пальный } \\
\text { пал }\end{array}$ \\
\hline $\begin{array}{c}\text { Количество дел об } \\
\text { оспаривании данного вида } \\
\text { НПА }\end{array}$ & 0 & 17 & 15 & 30 & 148 \\
$\begin{array}{c}\text { Количество НПА, } \\
\text { признанных недействующими } \\
\text { полностью или в части } \\
\text { Процент признания НПА } \\
\text { недействующими }\end{array}$ & 0 & 2 & 10 & 14 & 77 \\
\hline
\end{tabular}

В условиях неоднородности подходов субъектов АКЭ и противоречивой правоприменительной практики была предложена следующая шкала для оценивания наличия (отсутствия) коррупциогенного фактора в проекте НПА:

а) «выявленный коррупциогенный фактор (наименование фактора) влечет необходимость разработки нового проекта НПА»;

б) «выявленный коррупциогенный фактор (наименование фактора) влечет необходимость внесения изменений в настоящий проект НПА»;

в) «коррупциогенные факторы не выявлены».

Для мониторинга действующих НПА была предложена следующая модификация шкалы:

a) «выявленный коррупциогенный фактор (наименование фактора) влечет необходимость разработки проекта НПА о внесении изменений в настоящий НПА»;

б) «коррупциогенные факторы не выявлены». 
Таблица 8. Параметры НПА и коэффициенты риска присутствия коррупциогенных факторов

\begin{tabular}{|c|c|}
\hline Параметры НПА & $\begin{array}{c}\text { Коэффициент риска присутствия } \\
\text { коррупциогенного фактора }\end{array}$ \\
\hline \multicolumn{2}{|l|}{ Год принятия НПА: } \\
\hline 1993 & 1,1 \\
\hline 1994 & 0 \\
\hline $1995-2003$ & 0 \\
\hline 2004 & 0 \\
\hline 2005 & 1,1 \\
\hline 2006 & 4,4 \\
\hline 2007 & 3,3 \\
\hline 2008 & 12,1 \\
\hline 2009 & 4,4 \\
\hline 2010 & 18,7 \\
\hline 2011 & 6,6 \\
\hline 2012 & 22 \\
\hline 2013 & 8,8 \\
\hline 2014 & 9,9 \\
\hline 2015 & 16,5 \\
\hline 2016 & 8,8 \\
\hline 2017 & 2,2 \\
\hline 2018 & 1,1 \\
\hline \multicolumn{2}{|l|}{ Сфера правового регулирования: } \\
\hline сфера налогового права & 1,04 \\
\hline сфера финансового права & 5,2 \\
\hline сфера права социального обеспечения & 7,28 \\
\hline сфера земельного и градостроительного права & 15,6 \\
\hline сфера административного права & 37,44 \\
\hline сфера иного публичного права & 37,44 \\
\hline сфера трудового права & 0 \\
\hline сфера жилищного права & 3,12 \\
\hline сфера гражданского права & 1,04 \\
\hline сфера иного частного права & 0 \\
\hline \multicolumn{2}{|l|}{ Уровень НПА: } \\
\hline Федеральный закон & 0 \\
\hline Федеральный подзаконный НПА & 2,04 \\
\hline Региональный закон & 10,2 \\
\hline Региональный подзаконный НПА & 14,28 \\
\hline Муниципальный акт & 77,52 \\
\hline
\end{tabular}

Применение методов автоматизации к конкретному НПА позволяет установить степень риска наличия в нем коррупциогенного фактора. Коэффициент риска (см. Табл. 8) рассчитывался как процент выявления конкретного коррупциогенного фактора от общего числа выявленных коррупциогенных факторов.

\section{Заключение}

В юридической литературе представлено достаточно работ, посвященных именно правовым аспектам АКЭ. Однако вопросы, касающиеся непосредственно ее автоматизации, внедрения искусственного интеллекта не разработаны, а привлекли внимание исследователей лишь в последние годы (см. [15]). Выполненное исследование направлено на систематизацию причин, выявление условий для снижения объема работ АКЭ на основе методов крауд-интеллекта.

После рассмотрения коррупциогенных факторов согласно методологии АКЭ и проведения статистической обработки с классификацией НПА по уровням и сферам 
действия, мы можем сделать предварительный вывод, что автоматизация экспертизы возможна, как минимум для часто встречающихся факторов. В работе мы также провели пилотную разметку юридических документов и извлекли мета-данные из выборки актов в нескольких категориях: год принятия, область и уровень акта. Наконец, в ходе исследования мы рассмотрели возможности автоматизации АКЭ и выделили в ней следующие этапы:

1. Автоматизированный анализ НПА на предмет определения степени риска наличия в нем КФ.

2. Предварительное распределение НПА на подлежащие экспертизе и не подлежащие.

3. Распределение подлежащих АКЭ нормативных правовых актов на группы по степени риска наличия признаков коррупции.

4. Выделение группы с определением высокой степени риска наличия КФ для направления на АКЭ, которая проводится несколькими экспертами независимо. При противоречии в их выводах ввести контроль на необходимость повторной экспертизы экспертом, не участвовавшим в ее проведении.

Ограничением нашего исследования является, прежде всего, отсутствие анализа текста юридических документов в разрезе автоматически идентифицируемых корупциогенных факторов. Это является основным направлением наших дальнейшей работы, как и более подробная разметка юридических документов, позволяющая применение моделей машинного обучения для определения наличия факторов.

Работа выполнена при поддержке Российского фонда фундаментальных исследований, грант № 17-32-01087-ОГН.

\section{Литература}

[1] Федеральный закон от 25.12.2008 № 273-Ф3 «О противодействии коррупции» // Российская газета. № 266. 30.12.2008.

[2] Федеральный закон от 17.07.2009 № 172-Ф3 «Об антикоррупционной экспертизе нормативных правовых актов и проектов нормативных правовых актов» // Российская газета. № 133. 22.07.2009.

[3] Постановление Правительства Российской Федерации от 26.02.2010 № 96 «Об антикоррупционной экспертизе нормативных правовых актов и проектов нормативных правовых актов» // Российская газета. № 46. 05.03.2010.

[4] Приказ Минюста России от 01.04.2010 № 77 «Об организации работы по проведению антикоррупционной экспертизы нормативных правовых актов субъектов Российской Федерации и уставов муниципальных образований» // Российская газета, № 84, 21.04.2010.

[5] Статистические данные министерства юстиции Новосибирской области. URL: http://minjust.nso.ru/page/2303 (дата обращения 02.02.2019).

[6] Статистические данные Правительства Новосибирской области. URL: http://www.nso.ru/page/26841 (дата обращения 15.02.2019).

[7] Статистические данные Министерства юстиции Российской Федерации. URL: http://minjust.ru/ru/activity/legislative/anticorrekspert/accredited_persons_as_anticorruption _experts (дата обращения 15.02.2019).

[8] Официальный сайт г. Новосибирска URL: https://novo-sibirsk.ru/dep/expertise/docs/ (дата обращения 03.03.2019).

[9] Официальный сайт Администрации Омской области URL: http://mec.omskportal.ru/ru/RegionalPublicAuthorities/executivelist/MEC/corruption.html (дата обращения 03.03.2019)

[10] Методические рекомендации по проведению правовой и антикоррупционной экспертизы нормативных правовых актов субъектов Российской Федерации и муниципальных образований (с иллюстрацией на конкретных примерах). - М.: ФБУ НЦПИ при Минюсте России, 2017. 56 с. 
[11] Противодействие коррупции: конституционно-правовые подходы: коллективная монография / С.А. Авакьян, И.П. Кененова, А.С. Ковлер и др.; отв. ред. и рук. авт. кол. С.А. Авакьян. М.: Юстицинформ, 2016. 512 с.

[12] Указ Президента РФ от 01.12.2016 № 642 «О Стратегии научно-технологического развития Российской Федерации» // Собрание законодательства РФ. 05.12.2016. № 49. Ст. 6887.

[13] Постановление Правительства РФ от 26.02.2010 № 96 «Об антикоррупционной экспертизе нормативных правовых актов и проектов нормативных правовых актов» // Российская газета от 5 марта 2010 г. № 46.

[14]Распоряжение Губернатора Томской области от 15.03.2007 № 133-р «О методике экспертизы нормативных правовых актов Томской области и их проектов на коррупциогенность» URL: http://docs.cntd.ru/document/951818835 (дата обращения 01.02.2019).

[15] Барабаш О.В. Критерии выявления коррупциогенных факторов в официальных документах: лингвистический анализ // Вестник Пензенского государственного университета. 2016. № 1 (13). С. 17-21.

[16] Kurcheeva G., Rakhvalova M., Rakhvalova D., Bakaev M. Mining and Indexing of Legal Natural Language Texts with Domain and Task Ontology // Chugunov A., Misnikov Y., Roshchin E., Trutnev D. (eds) Electronic Governance and Open Society: Challenges in Eurasia. EGOSE 2018. Communications in Computer and Information Science. Vol. 947. Springer, Cham, 2019.

\title{
Automation of Anti-Corruption Expertise of Legislative Acts with Machine Learning Labeled Data
}

\author{
D. Rakhvalova ${ }^{1}$, G. Kurcheeva ${ }^{1}$, M. Rakhvalova ${ }^{2}$, M. Bakaev ${ }^{1}$ \\ ${ }^{1}$ Novosibirsk State Technical University \\ ${ }^{2}$ Novosibirsk military Institute of National Guard Troops
}

In the current paper, dedicated to potential automation of anti-corruption expertise in legislation, we explore identification of corruption-prone factors in legal documents and their drafts. Particularly, we analyze the frequencies of the different corruption-prone factors and propose some approaches for assessing risk of their existence in a legal document. The frequency analysis considers the following parameters of the legal documents: the year of adoption, the legislation field, the level of the legal act. For the data labeling, we employed non-expert workers from our "crowd-intelligence" lab, who specialize in performing relatively elementary tasks in data annotation for machine learning. The results of our research suggest that efficiency of the anticorruption expertise can be further enhanced based on the "weak AI" methods, i.e. through supporting decision-making of expert lawyers.

Keywords: corruption prevention, legal monitoring, machine learning, data labeling

Reference for citation: Rakhvalova D., Kurcheeva G., Rakhvalova M., Bakaev M. Automation of Anti-Corruption Expertise of Legislative Acts with Machine Learning Labeled Data // The State and Citizens in the Electronic Environment. Vol. 3 (Proceedings of the XXII International Joint Scientific Conference «Internet and Modern Society», IMS-2019, St. Petersburg, June 19-22, 2019). - St. Petersburg: ITMO University, 2019. P. 66 - 77. DOI: 10.17586/2541-979X-2019-3$66-77$ 


\section{Reference}

[1] Federal law \#273-FZ of 25.12.2008 «On the corruption prevention» // Rossiyskaya gazeta, 266, 30.12.2008.

[2] Federal law \#172-FZ of 17.07.2009 «On the anti-corruption expertise of legal acts and their drafts» // Rossiyskaya gazeta, 133, 22.07.2009.

[3] Decree of the Russian Federation Government \#96 of 26.02.2010 «On the anti-corruption expertise of legal acts and their drafts»// Rossiyskaya gazeta, 46, 05.03.2010.

[4] Order of the Russian Ministry of Justice \#77 of 01.04.2010 «On organizing works of running anti-corruption expertise of legal acts of Regions of the Russian Federation and the Municipalitites »// Rossiyskaya gazeta, 84, 21.04.2010.

[5] Statistical Data. The Ministry of Justice of the Novosibirsk Region of Russia. Accessed at http://minjust.nso.ru/page/2303 on 02.02.2019.

[6] Statistical Data. The Government of the Novosibirsk Region of Russia. Accessed at http://www.nso.ru/page/26841 on 15.02.2019.

[7] Statistical Data. Ministry of Justice of the Russian Federation. Accessed at http://minjust.ru/ru/activity/legislative/anticorrekspert/ accredited_persons_as_anticorruption_experts on 15.02.2019.

[8] Official website of Novosibirsk city. URL: https://novo-sibirsk.ru/dep/expertise/docs/ (Accessed on 03.03.2019)

[9] Official website of Omsk Region's administration. URL: http://mec.omskportal.ru/ru/RegionalPublicAuthorities/executivelist/MEC/corruption.html (Accessed on 03.03.2019)

[10]Methodological recommendations for performing the legal and anti-corruption inspection of legal acts of Russian Federation subjects and municipalities (with concrete illustrative examples). Moscow: FBU NSPI of the Ministry of Justice of Russia, 2017, 56 p.

[11]Anti-corruption: constitutional and legal approaches: collection of works / S.A. Avakyan, I.P. Kenenova, A.S. Kovler et al., ed. by S.A. Avakyan. Moscow, Justitsform, 2016, 512 p.

[12]Decree of the President of the Russian Federation of 01.12.2016 \#642 "On the Strategy of Scientific and Technological Development of the Russian Federation," The Russian Legislation Collection. 05.12.2016. \#49. Article 6887.

[13]Degree of Tomsk Region's Governor \#133-r of 15.03.2007 «On the methods for inspecting legal acts in Tomsk region and their drafts for corruption-proneness» URL: http://docs.cntd.ru/document/951818835 (Accessed on 01.02.2019)

[14] Barabash O.V. "Criteria for identification of corruption-prone factors in official documents: linguistic analysis," Proceedings of Penza State University, 1 (13), p. 17-21, 2016.

[15] Kurcheeva G., Rakhvalova M., Rakhvalova D., Bakaev M. (2019) Mining and Indexing of Legal Natural Language Texts with Domain and Task Ontology. In: Chugunov A., Misnikov Y., Roshchin E., Trutnev D. (eds) Electronic Governance and Open Society: Challenges in Eurasia. EGOSE 2018. Communications in Computer and Information Science, vol 947. Springer, Cham. 